\title{
Knowledge, Practice, and Attitudes Toward End-of-Life Issues among Adults in Hawaii
}

\author{
Harumi Karel, Ana Zir, and Kathryn L. Braun \\ Center on Aging, University of Hawaii at Manoa
}

\begin{abstract}
The Center on Aging at the University of Hawaii is currently conducting the Enhancing Care for Hawaii's Ohana (ECHO) Project. Its purpose is to explore the mechanism to disseminate end-of-life (EOL) information to family caregivers and adults who are providing or helping older adults in Hawaii and to examine the effects of EOL information on people's knowledge, attitudes, and practice. An analysis of baseline data revealed that a majority of participants knew about a living will (83\%) and a Healthcare Power of Attorney (88\%). However, slightly less than a half of the participants had completed a living will and a Healthcare Power of Attorney (HPOA). As far as attitudes toward EOL were concerned, the majority of the ECHO participants felt favorably toward discussing (89\%) and planning (95\%) for EOL care even if death is far in the future. Although there were differences in knowledge, attitudes and practice among different racial groups, the differences were not significant. However, as expected, the older the person, the more likely he/she had an advance directive and had made funeral and burial arrangements.
\end{abstract}

(C) 2003 Californian Journal of Health Promotion. All rights reserved.

Keywords: End of Life, Advance Directives, Healthcare Power of Attorney, and Caregivers

\section{Introduction}

People often avoid or delay thinking and talking about end-of-life (EOL) issues. Regardless of ethnic/racial background, starting EOL discussions is not easy. The Patient SelfDetermination Act (PSDA) of 1990 requires that health care institutions in the United States receiving Medicare funds follow patient preferences for medical treatment as indicated in patients' advance directives (McLaughlin \& Braun, 1998). However, an advance directive (AD) that includes both the living will and the Healthcare Power of Attorney is still a relatively new concept for the majority of people (Hallenbeck \& Goldstein, 1999). In 2001, the Center on Aging at the University of Hawaii launched an information dissemination project on EOL issues called Enhancing Care for Hawaii's Ohana (ECHO), supported by a grant from the Administration on Aging (AOA), National Family Caregiver Support Program. This paper explores knowledge, attitudes, and practices relating to EOL issues among adults in Hawaii.

\section{Purpose of the Study}

The purpose of the three-year ECHO project is to provide culturally sensitive end-of-life information and training to multi-ethnic caregivers and people who are currently helping older adults in Hawaii. Based on the results of focus group sessions with community service providers and multi-ethnic caregivers, the following four booklets were developed by the Center on Aging:

1. Advance Care Planning: Making Choices Known

2. Planning Ahead: Funeral and Memorial Services

3. Preparing to Say Good-bye: Care for the Dying

4. Help for the Bereaved: Surviving and Adapting to Change 
A two-page survey is given to participants before and after the receipt of the four booklets. The purpose of the survey is to examine whether the four booklets and the additional supportive services (telephone support, caregiver training, and assistance from case managers), have any effect in changing people's knowledge, attitudes, and practice.

The participants are being recruited through caregiver support groups, home care service providers, volunteer organizations, senior centers, caregiver conferences, and seminars on EOL. Therefore, it is a convenience sample of adults who currently assist elderly in Hawaii. The goal is to recruit 600 adults for this project.

Since the project is an exploratory study, several adjustments were made during the project period with respect to the criteria of the participants, administration of surveys, and the survey instrument itself.

\section{Characteristics of the ECHO Participants}

By the end of August 2003, a total of 393 ECHO participants had completed the initial survey. Seventy-nine percent were female and $21 \%$ were male. About $12 \%$ of participants were under age $45,51 \%$ were between $45-64$, and $37 \%$ were 65 and older.

Race: Of the respondents, 55\% were Asian, 20\% Caucasian, 16\% Hawaiian/Pacific Islander, and $10 \%$ other ethnicities. Most of the Asians (60\%) were of Japanese origin, followed by Filipino (24\%). Among Hawaiian/Pacific Islanders, the majority was Hawaiian (74\%), followed by Samoan (20\%). The average length residency in Hawaii among participants who were not born in the United States was 25 years.

Religious affiliation: The vast majority of participants were Christian (66\%), followed by Buddhist (13\%), and other (12\%). Nine percent of respondents reported no religious affiliation. The characteristics of the ECHO participants are depicted in Table 1. Only Asians identified themselves as Buddhist. Independent of racial background, many participants were Christian. Among the three major racial groups, Caucasians had the highest percentage of people who did not belong to any religion (16\%), compared to Asians (9\%) and Hawaiian/Pacific Islanders (3\%). Younger participants $(<65)$ tended not to belong to any religion (11\%), as compared with those 65 and older (5\%).

\section{Knowledge}

Advance directives (AD) are legal documents that include both a living will and the Healthcare Power of Attorney (HPOA). A living will specifies the kinds of medical treatment an individual wants in the event he/she cannot make decisions due to health and/or mental conditions. The HPOA designates another person(s) to make crucial health care decisions in the event of incapacitation (McLaughlin \& Braun, 1998; Hallenbeck, \& Goldstein, 1999).

Among the people who responded to the question Do you know what a living will is? 83\% responded in the affirmative. More Caucasians (88\%) and Asians (86\%) knew about a living will than did Hawaiian/Pacific Islanders (64\%). More younger participants $(<65)$ knew about a living will than did participants 65 and older ( $87 \%$ vs. $74 \%$ ). However, the differences were not statistically significant.

To the question, "Do you know what a Healthcare Power of Attorney is?,” 88\% of participants responded affirmatively. Similar to a living will, more Caucasians (97\%) and Asians (89\%) knew about a HPOA than did Hawaiian/ Pacific Islanders (74\%). The difference in knowledge about the HPOA between younger (93\%) and older participants (80\%) was not significant.

In Hawaii, a total of seven organizations are providing hospice services. Eighty-three percent of participants knew about hospice. Again, more Caucasians (93\%) and Asians (85\%) knew about hospice than did Hawaiian/Pacific Islanders (73\%) but the difference was not significant (Table 2). More younger participants knew about hospice than did older participants, however, those aged 45-64 had more awareness of hospice than did any other age groups, and the difference was significant $(p<.001)$. 
Table 1

Characteristics of ECHO Participants

\begin{tabular}{|c|c|}
\hline Characteristics & Percentage \& Number \\
\hline Gender & $\mathrm{N}=393$ \\
Male & $20.9 \%(82)$ \\
Female & $79.1 \%(311)$ \\
\hline Age & $\mathrm{N}=387$ \\
$18-24$ & $.8 \%(3)$ \\
$25-44$ & $11.4 \%(44)$ \\
$45-54$ & $24.8 \%(96)$ \\
$55-64$ & $26.4 \%(102)$ \\
$65-74$ & $19.9 \%(77)$ \\
$75-84$ & $14.5 \%(56)$ \\
$85+$ & $2.3 \%(9)$ \\
\hline Race & $\mathrm{N}=391$ \\
Caucasian & $19.7 \%(77)$ \\
Asian & $54.5 \%(213)$ \\
Hawaiian/Pacific Islander & $15.6 \%(61)$ \\
Other & $10.2 \%(40)$ \\
\hline Birthplace & $\mathrm{N}=388$ \\
Hawaii & $61.9 \%(240)$ \\
Mainland USA & $18.8 \%(73)$ \\
Other & $19.3 \%(75)$ \\
\hline Religion & $\mathrm{N}=382$ \\
Buddhist & $13.4 \%(51)$ \\
Christian & $65.7 \%(251)$ \\
Other & $12.0 \%(46)$ \\
None & $8.9 \%(34)$ \\
\hline
\end{tabular}

Table 2

Knowledge about Advance Directives and Hospice

\begin{tabular}{|l|c|c|c|}
\hline & Living Will (n) & HPOA (n) & Hospice (n) \\
\hline Total respondents & $83 \%$ & $88 \%$ & $83 \%$ \\
& $(311 / 377)$ & $(322 / 366)$ & $(326 / 388)$ \\
\hline Age & $\mathrm{N}=371$ & $\mathrm{~N}=363$ & $\mathrm{~N}=381$ \\
\hline Less than 65 & $87 \%(208 / 239)$ & $93 \%(219 / 236)$ & $89 \%(217 / 243)$ \\
65 and above & $74 \%(98 / 132)$ & $80 \%(101 / 127)$ & $76 \%(105 / 138)$ \\
\hline & & & \\
\hline Race & $\mathrm{N}=375$ & $\mathrm{~N}=364$ & $\mathrm{~N}=385$ \\
\hline Caucasian & $88 \%(65 / 74)$ & $97 \%(68 / 70)$ & $93 \%(69 / 74)$ \\
Asian & $86 \%(178 / 206)$ & $89 \%(176 / 197)$ & $85 \%(180 / 212)$ \\
Hawaiian/Pacific Islanders & $64 \%(36 / 56)$ & $74 \%(43 / 58)$ & $72 \%(43 / 60)$ \\
Other & $80 \%(31 / 39)$ & $87 \%(34 / 39)$ & $85 \%(33 / 39)$ \\
\hline
\end{tabular}




\section{Practice}

Does knowledge equate with people's practice? Forty-eight percent of participants had executed some type of advance directive. As expected, participants 65 and older were more likely to have a living will than their younger counterparts (54\% vs. $44 \%)$. Completion rates of living wills among Hawaiian/Pacific Islanders were slightly lower $(41 \%)$ than for Caucasians (50\%) or Asians (51\%), but the difference was not significant.

As far as the Healthcare Power of Attorney was concerned, $42 \%$ of participants had executed an HPOA. Similar to the living will, Hawaiian/ Pacific Islanders had a slightly lower completion rate for the HPOA (36\%) than did Caucasians (44\%) and Asians (45\%), but the differences were not significant.
Does religion influence people in any way to prepare for dying and death? Among participants of the ECHO project, religious affiliation did not affect whether or not a person had a living will or an HPOA.

Questions regarding funeral and burial arrangements were added to the survey in 2002.

Forty percent of participants had made funeral arrangements, and $43 \%$ had a burial plan. As expected, a greater percentage of older participants (65 and above) had made funeral and burial arrangements than had younger participants and the difference was significant $(\mathrm{p}<.001)$. Although fewer Caucasians had made funeral and burial arrangements than had Asians and Hawaiian/Pacific Islanders, these differences were not statistically significant (Table 3).

Table 3

Completion of Advance Directives and Funeral/Burial Arrangements

\begin{tabular}{|l|c|c|c|c|}
\hline & $\begin{array}{c}\text { Living Will } \\
\text { (n) }\end{array}$ & $\begin{array}{c}\text { HPOA } \\
\text { (n) }\end{array}$ & $\begin{array}{c}\text { Funeral } \\
\text { (n) }\end{array}$ & $\begin{array}{c}\text { Burial } \\
\text { (n) }\end{array}$ \\
\hline Total completion of the & $48 \%$ & $42 \%$ & $40 \%$ & $43 \%(89 / 208)$ \\
following arrangement & $(174 / 364)$ & $(150 / 356)$ & $(84 / 209)$ & \\
\hline Age & $\mathrm{N}=358$ & $\mathrm{~N}=351$ & $\mathrm{~N}=207$ & $\mathrm{~N}=206$ \\
\hline Less than 65 & $44 \%(101 / 231)$ & $39 \%(92 / 236)$ & $28 \%(33 / 116)$ & $28 \%(32 / 116)$ \\
65 and above & $54 \%(69 / 127)$ & $48 \%(55 / 115)$ & $55 \%(50 / 91)$ & $63 \%(57 / 90)$ \\
\hline & & & & \\
\hline Race & $\mathrm{N}=362$ & $\mathrm{~N}=354$ & $\mathrm{~N}=208$ & $\mathrm{~N}=207$ \\
\hline Caucasian & $50 \%(35 / 70)$ & $44 \%(31 / 71)$ & $29 \%(10 / 35)$ & $37 \%(13 / 35)$ \\
Asian & $51 \%(100 / 198)$ & $45 \%(84 / 188)$ & $41 \%(47 / 115)$ & $42 \%(48 / 114)$ \\
Hawaiian/Pacific Islanders & $41 \%(23 / 56)$ & $36 \%(20 / 56)$ & $49 \%(18 / 37)$ & $49 \%(18 / 37)$ \\
Other & $40 \%(15 / 38)$ & $36 \%(14 / 39)$ & $38 \%(8 / 21)$ & $43 \%(9 / 21)$ \\
\hline
\end{tabular}

\section{Attitude}

Not everyone answered the question, "If it were possible, would you want to die at home?" Among participants who responded, 60\% preferred to die at home but $17 \%$ did not. For those who wished to die at home, the familiar environment surrounded by loved ones was the major reason. Among people who did not want death to occur at home, many of them stated that they didn't want to burden family members. Others mentioned that death at home would cast a spell on the residence and sadness would remain at home. Also, 23\% were not sure about where they wanted to die. Many of those unsure about the place of death stated that it would be dependent upon the situation or circumstances at that time.

Although slightly more Caucasians wanted to die at home (69\%) than Asians (57\%) and Hawaiian/Pacific Islanders (58\%), the difference was not significant. More younger participants 
$(<65)$ wanted to die at home $(64 \%)$ compared with participants 65 and older (53\%), yet the difference was not statistically significant.

Among participants who responded to the questions asking about end-of-life preparation:

1. $89 \%$ agreed that it was a good idea to talk about the end of life with their family even if death is far in the future.

2. $95 \%$ agreed that it was a good idea to make plans for the end of life even it death is far in the future.

3. $95 \%$ agreed that while still healthy, an individual should pick a family member or friend to make decisions in the event he/she were too sick to make them.

Therefore, a majority of the ECHO participants preferred to talk about and plan for the end of life. There were no age or racial differences regarding preferences.

\section{Discussion/Summary}

The research study conducted in Hawaii in 1998 indicated that $29 \%$ of Hawaii residents had a living will, 22\% had a HPOA, and 65\% preferred to die at home (Braun, Onaka, \& Horiuchi, 2001). The results of this study suggest a much larger percentage of people had a living will and a HPOA. Some of the reasons for the higher turnout were:

1. The sample was not randomly selected. The participants were recruited from caregiver support groups, community service organizations, caregiver conferences and seminars. Thus, it might have attracted people who were more aware of end-of-life issues.
2. There is widespread information about advance directives today as compared to 1998, thus more people know about them and have completed the document.

Initially, recruitment of caregiver-participants was difficult for the following reasons: 1) Few people identified themselves as caregivers; 2) Community service providers were not comfortable talking about EOL with their clients/caregivers; 3) Survey questionnaires were too long; and 4) People were simply not interested in learning about EOL issues. For example, an introductory seminar was arranged at four senior centers in Honolulu. One center canceled the seminar due to a lack of interest among senior center participants. Only two to three elderly attended the introductory seminar at the remaining senior centers. Anecdotal information from the senior center operators indicated that the many seniors come to the senior center to enjoy their lives and be active and not to think about death and dying. Therefore, it is still very difficult to disseminate or educate people about end-of-life issues because a majority of people still seem to avoid the issues until the last minute or leave the entire decision up to the remaining family members.

Although slight differences were noted among different racial groups, the difficulty of educating people about EOL seemed to do more with the culture of denying death. Additional efforts are needed to inform and educate people about EOL issues. Planning ahead for the end of life can improve the quality of people's lives as well as their deaths. Increased awareness of documents such as the advance directive (AD) and Healthcare Power of Attorney (HPOA) and learning about the dying and the grieving process are vital elements toward this end.

\section{References}

Braun, K. L., Onaka, A. T., and Horiuchi, B. Y. (2001). Advance directive completion rates and end-oflife preferences in Hawaii. Journal of the American Geriatrics Society. 49, 1708-1713.

McLaughlin, L. A., and Braun, K. L. (1998). Asian and Pacific Islander cultural values: Considerations for health care decision making. Health and Social Work, 23, 116-126.

Hallenbeck, J., and Goldstein, M. K. (1999). Decisions at the end of life: Cultural considerations beyond medical ethics. Generations, 23(1), 24-29.

Braun, K. L., and Browne, C. (1998). Perceptions of dementia, caregiving, and help seeking among Asian and Pacific Islander Americans. Health and Social Work, 23, 262-274. 


\title{
Acknowledgements
}

This study is currently being funded by the Administration on Aging, National Family Caregiver Support Grant \# 90-CG-2548.

\author{
Author Information \\ Harumi S. Karel, $\mathrm{PhD} *$ \\ Kathryn L. Braun, Dr. PH \\ Ana Zir, MPH \\ Center on Aging \\ John A. Burns School of Medicine \\ University of Hawaii at Manoa \\ E-Mail: kharumi@hawaii.edu \\ E-Mail: kbraun@hawaii.edu \\ E-Mail: anazir@hawaii.edu \\ * corresponding author
}

